Publisher homepage: www.universepg.com, ISSN: 2663-7529 (Online) \& 2663-7510 (Print)

https://doi.org/10.34104/ejmhs.021.01470160

European Journal of Medical and Health Sciences

Journal homepage: www.universepg.com/journal/ejmhs

\title{
Impact of COVID-19 Pandemic on Population-Level Interest in Skincare: Evidence from a Google Trends
}

\author{
Hasan Symum ${ }^{1}$, Md. F. Islam ${ }^{2}$, Habsa K. Hiya ${ }^{3}$, and Kh Mohammad Ali ${ }^{4}$ \\ ${ }^{1}$ Dept. of Industrial and Management System Engineering, University of South Florida, Tampa, FL, USA; ${ }^{2}$ Dept. of Industrial \\ Engineering and Management, Khulna University of Engineering \& Technology, Khulna, Bangladesh; ${ }^{3}$ MUMA College of \\ Business, University of South Florida, Tampa, Florida, United States; ${ }^{4}$ Dhaka Medical College Hospital, Dhaka, Bangladesh. \\ *Correspondence: hsymum@usf.edu (Hasan Symum, Dept. of Industrial and Management System Engineering, University \\ of South Florida, Tampa, FL, USA).
}

\begin{abstract}
COVID-19 pandemic created an unprecedented disruption of daily life including the pattern of skincare in healthcare settings by issuing stay-at-home orders around the world. There has been limited information about trends of skincare related public interest during CVOID-19 and whether any substantial disruption in population-level behavior. The objective of this study is to evaluate the change in skincare-related population interest around the world during the COVID-19 pandemic time. Weekly RSV data were extracted worldwide and 25 counties between August 1, 2016, and August 31, 2020. Interrupted time-series analysis was conducted as the quasi-experimental approach to evaluate the longitudinal effects of COVID-19 skincare-related search queries. For each country, autoregressive integrated moving average (ARIMA) model relative search volume (RSV) time series and then testing multiple periods simultaneously to examine the magnitude of the interruption. Multivariate linear regression was used to estimate the correlation between the relative changes in RSV with COVID-19 confirmed cases/ per million population and lockdown measures. Of 25 included countries in our study, 17 showed significantly increased $(\mathrm{p}<0.01)$ RSVs during the lockdown period compared with ARIMA forecasted data. The highest percentage of increments occurs in May and June in most countries. There was also a significant correlation between lockdown measures and the number of COVID-19 cases with relative's changes in population interests for skincare. Understanding the trend and changes in skincare public interest during COVID-19 may assist health authorities to promote accessible educational information and preventive initiatives regarding skin problems.
\end{abstract}

Keywords: COVID-19, Skincare, ARIMA, Dermatology, Social distancing, and Time-series analysis.

\section{INTRODUCTION:}

Corona Virus Disease 2019 (COVID-19) is a novel type of coronavirus, SARS-CoV-2, first detected in Wuhan (Hubei), China on December 31, 2019 (Wang et al., 2020). Due to the continuous increment of new cases WHO (World Health Organization) first called it an international emergency on January 31, 2020, then later on March 11, 2020, it was declared as a pandemic UniversePG I www.universepg.com
(Timeline: WHO's COVID-19 response, World Health Organization., 2020). On September 10, 2020, the total reported cases were approximately 27.5 million in more than 213 countries and territories around the world with a mortality rate of $4.30 \%$ and daily cases of 258,000 (COVID-19 Data Repository by the Center for Systems Science and Engineering (CSSE). Johns Hopkins University, 2020; Dong, Du and Gardner, 
2020). To restrict the propagation of new cases, lots of preventive measures (international flight ban, social distancing, mass gathering ban, issuing stay home, etc.) were taken around the world. This restriction has brought significant disruption in daily life due to a lack of proper and regular physical activity. Besides the increase of screen exposure leads the young generation to the sleepless problem. (Majumdar, Biswas and Sahu, 2020) Besides people with dysmorphic concerns who are obsessed with an imagined or slight defect in physical appearance usually visit skincare service regularly during the normal time, may not be able to receive service due to "Stay Home" order, and consequently have higher anxiety and depression (Pikoos et al., 2020). Besides, dermatitis patients with skin problems (e.g, hair and scalp diseases) who are usually required to take regular treatment from health service providers, also suffer from this situation(Turkmen et $a l ., 2020)$. With the increase of internet users around the globe, Infodemiology has become a very useful informatics concept, especially for epidemic and pandemic situations (JMIR Publications. E-collection 'Infoveillance, Infodemiology, Digital Disease Surveillance, Infodemic Management'; The Journal of Medical Internet Research. E-collection 'JMIR Theme Issue 2020/21: COVID-19 Special Issue'). The term Infodemiology was coined by Gunther Eysenbach and defined as "the science of distribution and determinants of information in an electronic medium, specifically the Internet, or in a population, with the ultimate aim to inform public health and public policy" (Eysenbach, 2009). Through understanding, Web search trends the Infodemiology study can provide valuable information about public interest and awareness in health emergencies as a proxy for public health risk perception (Eysenbach, 2011; Spiegelman et al., 2020). Prior studies used internet search queries to model the outbreak of infectious diseases (e.g., dengue, and influenza), track substance usages, and monitor public behavior (JMIR Publications. E-collection 'Infodemiology and Infoveillance', no date; JMIR Publications; E-collection 'Infoveillance, Infodemiology, Digital Disease Surveillance, Infodemic Management; MAvragani, 2020). More recently, researchers showed promise in modeling seasonal variation of the chronic and acute dermatologic condition through public web searches pattern (Kardeş, 2019; UniversePG I www.universepg.com
Ravipati and Pradeep, 2020). Internet search queries have been widely used by adopted by researchers to investigate public interest, health awareness, and mental health in the COVID-19 pandemic situation (Bernardo et al., 2013; Nuti et al., 2014; Mavragani, Ochoa and Tsagarakis, 2018; Allauddin et al., 2021).

Several studies have done using Google Trends for monitoring the impact of COVID-19 on public interests on health literacy, dental problems, mental health conditions, and elective surgery operations (Heerfordt, 2020; Effenberger et al., 2020; Mahmudi et al., 2020; Spiegelman et al., 2020; Symum et al., 2020; Walker et al., 2020). Furthermore, several recent studies showed significant potential in monitoring medical conditions such as rheumatic diseases and associated treatments using Google Trends-based web search analysis (Kardeş et al., 2020, 2021). Google Trends also used to correlate COVID-19 pandemicrelated anxiety and depression with the health precaution-related search queries (Lin, Liu and Chiu, 2020). Amid the COVID-19 pandemic, individual routine skincare and dermatologic treatment behavior have been widely disrupted due to dermatologists' unavailability and limited supply of skincare products. Similar to other medical and mental conditions, understanding the pattern of web searches can be used to understand variations in dermatologic conditions, cosmetic procedures, and skincare behavior (Guzman and Barbieri, 2020; Ravipati and Pradeep, 2020). There have been limited studies about the impact of COVID19 in the dermatological study using web queries. Recently, three studies thus far attempted to empirically understand the impact of COVID-19 on dermatologic conditions and procedures. However, these studies either limited to an initial period of COVID-19 ( e.g., 2 January 2020- 12 May 2020), did not consider historical trend and seasonality in RSV values, and perform the robust statistical comparison between pre and during COVID RSV values (Guzman and Barbieri, 2020; Searle, Al-Niaimi and Ali, 2020). Furthermore, this study has been conducted for the UK, the United States, Italy, and Turkey, and the effect of COVID-19 on skincare interests has not been reported elsewhere (Guzman and Barbieri, 2020; Kutlu, 2020; Searle, AlNiaimi and Ali, 2020). Therefore, we aimed to determine in our study whether there is any significant 
change in the public interest in skincare around the world during COVID-19 by using Google Trends.

\section{METHODS:}

\section{COVID-19 Case Data}

Daily data on laboratory-confirmed cases and deaths were collected in the COVID-19 web tracker by the Johns Hopkins University Center for Systems Science and Engineering (CSSE)(COVID-19 Data Repository by the Center for Systems Science and Engineering (CSSE), Johns Hopkins University, 2020). Daily confirmed COVID-19 cases and related death were retrieved for the 23 countries and worldwide from the timeframe of January 22, 2020, to August 31, 2020.

\section{Country-Specific Data}

Information on COVID-19 related lockdown restriction and stay home order duration were obtained from each state and country's official health website. Weekly seasonally adjusted national and state insured unemployment rates were obtained from the World bank website from January 22, 2020, to August 31, 2020 (Unemployment Insurance Weekly Claims Data. United States Department of Labor). The total population by the country was retrieved for 2019 and, later used to calculate per million COVID-19 cases. Skin disease-related (per 100 thousand population) in the individual were also included in our study from the national disease burden study for the year 2016 .

\section{Country Selection Criteria}

Inclusion criteria for selecting countries in our study were as (1) More than 100 deaths per million due to COVID-19 till August 31, 2021, (2) A population more than one million for year 2019 (3) Higher than $50 \%$ access to the internet for second quarter 2020 . These criteria were selected based on population estimates, internet user penetration and COVID-19 fatality rate. The rationale for our inclusion criteria of population more than one million and more than $50 \%$ internet access was that Google Trends does not always have enough total Google Search queries, which depend on population and Internet access( Mahmudi et al., 2020). In addition, with fewer internet access, Google Trends might not be able assess population health behavior of the overall country. Countries with more deaths due to COVID-19 had more likely to implement strictly measures. Besides, the COVID-19 fatality rate can also approximate the total burden of UniversePG I www.universepg.com
COVID-19 by adjusting for population among countries. Country wise internet access data were retrieved from internetstat.com website for the second quarter 2020.

\section{Google Trends Data}

This Google Trends-based Infodemiology study followed the methodological framework which has been widely accepted by prior studies (Mavragani and Ochoa, 2019). In this study, Google Trends topic "Skin care" was used to retrieve RSV values as a surrogate measure of population interest rate in skincare. According to the google Trends website, topics are a group of terms that share the same concept in any language (Compare Trends search terms).Therefore, Google Trends topic "Skin care" rather than any search term to avoid heterogeneity in the analysis due to language difference. Google Trends topic "skincare" comprises a group of search terms that share the same concept (i.e., skincare-related search) in any language.

\section{Google Trends Region and Period Selection}

The search queries were specified to the selected countries as a geographic area to avoid mixing with search queries originating elsewhere. Data were retrieved on a weekly basis from Google Trends from January 1, 2016, to August 31, 2020. This particular time frame was chosen in order to better capture the temporal trend and variation of the skincare-related population interest, monitoring the internet-related activity before (i.e., population interest baseline period) and during the COVID-19 pandemic. Categories and subcategories were not selected when searching for Google Trends topic for the countries.

\section{Statistical Analysis}

Interrupted time-series analysis was conducted as the quasi-experimental approach to evaluate the longitudinal effects of COVID-19 on skincare-related search queries around the world (Hudson, Fielding and Ramsay, 2019; Ewusie et al., 2020). For this timeseries analysis, the initial step was to identify the best fit autoregressive integrated moving average (ARIMA) model for each countries' pre-COVID-19 time ( January 1, 2016 - March 1, 2020) RSV values. After the identification of the best-fitted model, the magnitude of the COVID-19 interruption on skincare public interest was examined for multiple periods during COVID-19 times. Based on previous literature, 
ARIMA modeling is appropriate for our study considering the transient and permanent effect of COVID19 interruption by taking account of dependency and seasonality between data points in time series (Troelstra et al., 2016; Jabaley et al., 2018). The four steps BoxJenkins methodology was used to select the best fitting ARIMA model for each country and this approach has been widely used in modeling time series interruptions (Box et al., 2015). Box-Jenkins methodology is an interactive approach that consists of the following steps of Model Identification, Estimation, Diagnostic Checking, and Forecasting. In the model identification step, seasonality in the dependent series and autocorrelation are identified sing plots of the autocorrelation and partial autocorrelation functions. Then, the estimation step involves using numerical methods to arrive at coefficients that best fit the selected ARIMA model though minimizing model error. The diagnostic checking step looks into evidence whether the selected model is a good fit for the data based on over fitting and residual error. Finally, the forecast step predicts the future value based on the selected final ARIMA model. The models were used to estimate the association of COVID-19 interruptions with skincare interest in the selected countries. To assess the effect of the COVID-19, six COVID-19 effect periods were distinguished, for every month after March 11, 2020, until August 31, 2021. This method was chosen to minimize the number of effect periods, in order to avoid the risks of multiple testing (JMIR Publications. E-collection 'Infoveillance, Infodemiology, Digital Disease Surveillance, Infodemic Management). For each of the country RSV values, the respective periods were modeled as binary interruption dummies coded ' 1 ' for the duration of the period and coded ' 0 ' for the period before and after that period of interruption. For example, for the interruption period of April during COVID-19 time, this specific interruption variable was only coded as ' 1 ' for the April RSV values, and all other weeks were coded as ' 0 '. Similarly, for the effective period of July during the COVID-19 period, a variable was added in which month July was coded as ' 1 ', and all other times were coded as ' 0 '. Effect sizes and confidence intervals were estimated for each period and a p-value is estimated using $F$ statistics. The effect size was measured in the relative changes (\%) in $\mathrm{RSV}$ to the expected level without the occurrence of UniversePG I www.universepg.com
COVID-19 restrictions for each period. Besides, we also used a multivariate linear regression model to estimate the correlation between the country's relative changes in RSV after $11^{\text {th }}$ March with COVID-19 confirmed cases per million, lockdown orders, after adjusting covariates of the unemployment growth, skin disease rate, and internet user rates. All the statistical analyses were performed using $\mathrm{R}$ and a $\mathrm{p}$-value less than 0.05 was considered significant for effect sizes. IRB approval was not required because this study did not involve human subjects.

\section{RESULTS:}

Worldwide relative search volume (RSV) for skincare has increased continuously after WHO (World Health Organization) declared COVID-19 as a global pandemic on March 11, 2020, and it continued until May 09, 2020. After that, the rate of RSV was decreased slightly but still, it remains higher in many countries. The worldwide interest in skincare showed a significant increment in April (22.48\%, CI of [16.37, 28.60] \%) and reached the highest increment in May $(29.62 \%$, CI of $[22.23,37.00] \%)$. After May, the increment in worldwide RSVs started to slow down (Fig 1), but the trend is still significantly higher compared to the forecasted value in August (16.3\%, CI of $[6.08,26.53] \%)$. In our study, we selected 25 countries based on study design criteria. The majority of countries in this study are from the Americas and Europe while three countries are from Asia and one from the Africa continent (Supplementary Table 1). Among the selected countries, Chile has the most confirmed COVID-19 cases $(20,061)$ per million and Belgium has the most confirmed death rate per hundred thousand population. The lockdown style imposed in most countries was nationwide except five countries where Belgium, Canada, and the USA imposed state-based lockdown, and Chile and Russia imposed city-based lockdown. Out of 25 countries, 17 countries showed a significant $(\mathrm{p}<0.05)$ increment in RSVs during the lockdown period compared with the ARIMA forecasted data with a mean confidence interval (CI) of $95 \%$ (Table 1). The RSV trend in two Asian countries showed a varied impact during the COVID-19 pandemic and lockdown restriction measures. Compared with the forecasted value, Oman showed a significant increment in RSVs in May and 
August while there were no such significant changes in Kuwait and Iran. Besides, South Africa showed a significant increment in RSVs in March $(48.09 \%$, CI of $[32.62,63.55] \%)$ and April $(82.09 \%$, CI of [65.21, 98.98] \%) though from May the trends started to decrease. Among the countries in the Americas, the USA, Brazil, Canada, Chile, and Panama showed a stepper increase in RSVs at the beginning of the lockdown whereas Mexico, Columbia, and Ecuador showed a higher increment in the late period (Fig 2). The highest increment in RSV values for the Americas was found in Chile in August (153.39\%, CI of [129.21, $177.58] \%)$. In the USA, the highest percentage change of RSVs seen in May (42.63\%), and the trend still above the forecasted trend. The trends of Argentina and the Dominican Republic followed the forecasted

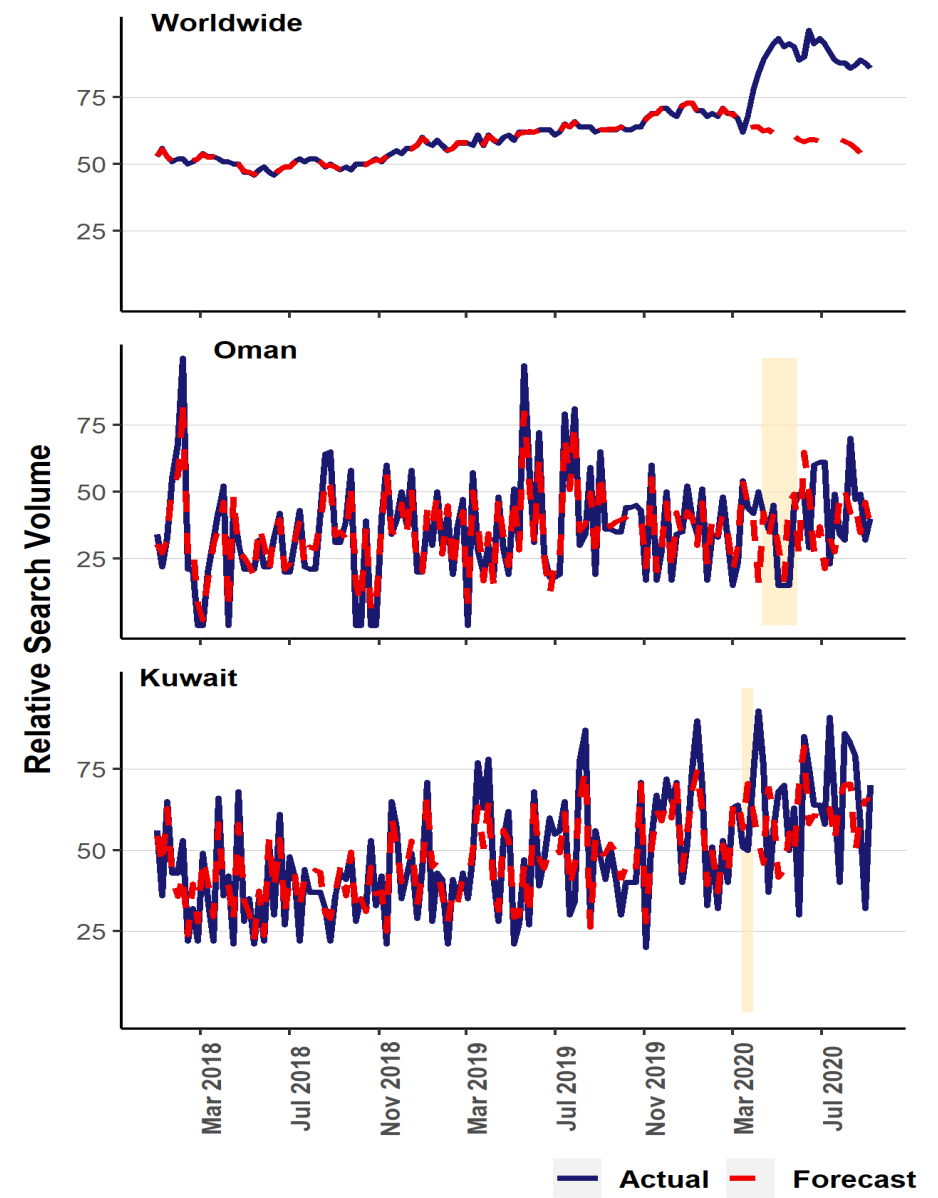

trend though there is still an unprecedented stepper increase in RSV values. Of all selected countries in the Americas, only Columbia and Ecuador showed a decrease in RSVs with no significant relationship. Like the Americas, European countries also showed the earlier stepper increase in RSVs with a significant percent increase except for Russia (Fig 3). Italy and Spain showed a significant increase in RSVs at the beginning of lockdown, though in the late part of the lockdown this change started to decrease. The UK had the most unprecedented trend in the RSVs, and the significant percent increase had seen on April 26 $(80.54 \%$, CI of $[70.39,90.69] \%)$. Although Germany and Spain had shown the earlier increment, the trend went down rapidly after the lockdown withdrew.
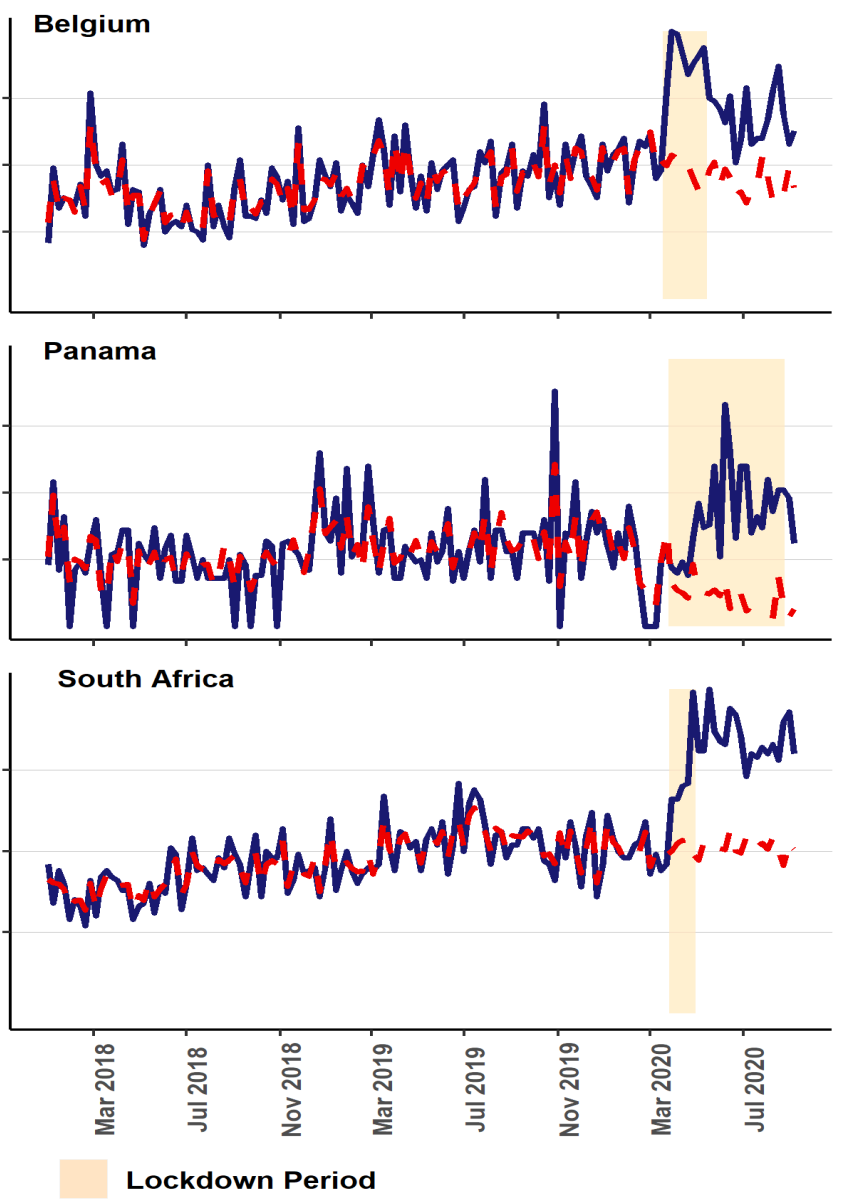

Fig 1: Actual and ARIMA forecasted mean RSV values in worldwide and five countries.

The association between lockdown measures and the number of COVID-19 cases was found significant from the multivariate linear regression analysis with a p-value of less than 0.05 (Table 2). After adjusting the covariates, skincare-related RSV value was found UniversePG I www.universepg.com positively associated (effect size of 0.001 and $p<0.01$ ) with daily COVID-19 cases. Besides, the presence of lockdown was also associated with the increment of skincare-related RSV values with an effect size of 3.681 and $\mathrm{p}<0.01$. 
Table 1: Monthly relative volume changes for skincare after COVID-19 pandemic.

\begin{tabular}{|c|c|c|c|c|c|c|}
\hline \multicolumn{7}{|c|}{ Percentage $(\%)$ relative search volume changes Mean $(95 \% \mathrm{CI})$} \\
\hline Country & March-2020 & April-2020 & May-2020 & June-2020 & July-2020 & August-2020 \\
\hline Worldwide & $\begin{array}{c}-4.13 \\
(-8.48,0.22)\end{array}$ & $\begin{array}{c}22.48 \\
(16.37,28.60)\end{array}$ & $\begin{array}{c}29.62 \\
(22.23,37.00)\end{array}$ & $\begin{array}{c}22.92 \\
(14.46,31.38)\end{array}$ & $\begin{array}{c}20.62 \\
(11.26,29.97)\end{array}$ & $\begin{array}{c}16.3 \\
(6.08,26.53)\end{array}$ \\
\hline Argentina & $\begin{array}{c}-2.83 \\
(-20.64,14.98)\end{array}$ & $\begin{array}{c}23.00 \\
(3.34,42.67)\end{array}$ & $\begin{array}{c}48.16 \\
(26.82,69.49)\end{array}$ & $\begin{array}{c}47.99 \\
(25.14,70.84)\end{array}$ & $\begin{array}{c}73.91 \\
(49.67,98.16)\end{array}$ & $\begin{array}{c}49.38 \\
(23.85,74.92)\end{array}$ \\
\hline Belgium & $\begin{array}{c}33.99 \\
(16.93,51.05)\end{array}$ & $\begin{array}{c}71.47 \\
(52.40,90.54)\end{array}$ & $\begin{array}{c}66.47 \\
(46.51,86.43)\end{array}$ & $\begin{array}{c}31.58 \\
(11.36,51.79)\end{array}$ & $\begin{array}{c}17.91 \\
(-3.18,39.00)\end{array}$ & $\begin{array}{c}31.75 \\
(11.02,52.47)\end{array}$ \\
\hline Brazil & $\begin{array}{c}38.63 \\
(30.03,47.24)\end{array}$ & $\begin{array}{c}87.93 \\
(75.36,100.51)\end{array}$ & $\begin{array}{c}88.08 \\
(73.36,102.80)\end{array}$ & $\begin{array}{c}71.53 \\
(55.19,87.88)\end{array}$ & $\begin{array}{c}75.97 \\
(58.14,93.80)\end{array}$ & $\begin{array}{c}47.74 \\
(28.09,67.40)\end{array}$ \\
\hline Canada & $\begin{array}{c}-17.03 \\
(-22.53,-11.53)\end{array}$ & $\begin{array}{c}31.83 \\
(26.17,37.50)\end{array}$ & $\begin{array}{c}43.77 \\
(37.50,50.04)\end{array}$ & $\begin{array}{c}40.95 \\
(34.50,47.9)\end{array}$ & $\begin{array}{c}24.07 \\
(18.05,30.10)\end{array}$ & $\begin{array}{c}27.24 \\
(21.25,33.22)\end{array}$ \\
\hline Chile & $\begin{array}{c}-2.12 \\
(-25.98,21.73)\end{array}$ & $\begin{array}{c}77.42 \\
(52.07,102.76)\end{array}$ & $\begin{array}{c}51.03 \\
(28.30,73.76) \\
\end{array}$ & $\begin{array}{c}138.37 \\
(112.91,163.84)\end{array}$ & $\begin{array}{c}131.23 \\
(107.22,155.24)\end{array}$ & $\begin{array}{c}153.39 \\
(129.21,177.58)\end{array}$ \\
\hline Colombia & $\begin{array}{c}-12.88 \\
(-27.73,1.97)\end{array}$ & $\begin{array}{c}-8.43 \\
(-26.98,10.13)\end{array}$ & $\begin{array}{c}8.61 \\
(-12.85,30.06)\end{array}$ & $\begin{array}{c}27.34 \\
(3.12,51.57)\end{array}$ & $\begin{array}{c}32.52 \\
(6.40,58.65)\end{array}$ & $\begin{array}{c}37.04 \\
(8.72,65.36)\end{array}$ \\
\hline $\begin{array}{c}\text { Dominican } \\
\text { Republic }\end{array}$ & $\begin{array}{c}53.08 \\
(4.01,102.15)\end{array}$ & $\begin{array}{c}66.15 \\
(15.76,116.53)\end{array}$ & $\begin{array}{c}86.68 \\
(35.01,138.35)\end{array}$ & $\begin{array}{c}66.15 \\
(13.22,-119.07)\end{array}$ & $\begin{array}{c}81.08 \\
(26.93,135.23)\end{array}$ & $\begin{array}{c}60.55 \\
(5.20,115.89)\end{array}$ \\
\hline Ecuador & $\begin{array}{c}-9.36 \\
(-46.66,27.94)\end{array}$ & $\begin{array}{c}-1.65 \\
(-41.45,38.15)\end{array}$ & $\begin{array}{c}-1.65 \\
(-43.80,40.50)\end{array}$ & $\begin{array}{c}63.92 \\
(19.54,108.29)\end{array}$ & $\begin{array}{c}54.28 \\
(7.78,100.77)\end{array}$ & $\begin{array}{c}92.84 \\
(44.32,141.36)\end{array}$ \\
\hline France & $\begin{array}{c}-2.40 \\
(-17.87,13.07)\end{array}$ & $\begin{array}{c}19.00 \\
(0.11,37.88)\end{array}$ & $\begin{array}{c}25.72 \\
(4.31,47.13)\end{array}$ & $\begin{array}{c}36.67 \\
(11.46,61.87)\end{array}$ & $\begin{array}{c}12.89 \\
(13.64,39.42)\end{array}$ & $\begin{array}{c}7.15 \\
(-20.72,35.02)\end{array}$ \\
\hline Germany & $\begin{array}{c}35.82 \\
(24.50,47.14)\end{array}$ & $\begin{array}{c}24.77 \\
(13.71,35.83) \\
\end{array}$ & $\begin{array}{c}20.56 \\
(8.61,32.51)\end{array}$ & $\begin{array}{c}19.66 \\
(6.50,32.82)\end{array}$ & $\begin{array}{c}15.70 \\
(2.45,28.96)\end{array}$ & $\begin{array}{c}3.22 \\
(-10.41,16.86)\end{array}$ \\
\hline Iran & $\begin{array}{c}-8.05 \\
(-8.38,-7.11)\end{array}$ & $\begin{array}{c}-27.17 \\
(-28.58,15.81)\end{array}$ & $\begin{array}{c}-15.55 \\
(-14.29,29.41)\end{array}$ & $\begin{array}{c}-11.98 \\
(-10.89,26.28)\end{array}$ & $\begin{array}{c}2.92 \\
(-2.53,24.87)\end{array}$ & $\begin{array}{c}2.23 \\
(-7.42,11.63)\end{array}$ \\
\hline Italy & $\begin{array}{c}16.64 \\
(-1.15,34.43)\end{array}$ & $\begin{array}{c}56.55 \\
(36.57,76.54)\end{array}$ & $\begin{array}{c}49.96 \\
(26.19,73.73)\end{array}$ & $\begin{array}{c}9.33 \\
(-16.80,35.45)\end{array}$ & $\begin{array}{c}12.18 \\
(-16.42,40.78)\end{array}$ & $\begin{array}{c}6.50 \\
(-24.18,37.17)\end{array}$ \\
\hline Kuwait & $\begin{array}{c}59.29 \\
(7.67,110.90)\end{array}$ & $\begin{array}{c}35.89 \\
(-4.59,76.37)\end{array}$ & $\begin{array}{c}36.16 \\
(-7.38,79.70)\end{array}$ & $\begin{array}{c}39.23 \\
(-6.25,84.72)\end{array}$ & $\begin{array}{c}8.94 \\
(-34.38,52.25)\end{array}$ & $\begin{array}{c}10.05 \\
(-32.87,52.98)\end{array}$ \\
\hline Mexico & $\begin{array}{c}-3.34 \\
(-17.50,10.83)\end{array}$ & $\begin{array}{c}6.42 \\
(-8.83,21.67)\end{array}$ & $\begin{array}{c}38.36 \\
(21.32,55.39)\end{array}$ & $\begin{array}{c}62.01 \\
(43.51,80.51)\end{array}$ & $\begin{array}{c}74.34 \\
(54.51,94.17)\end{array}$ & $\begin{array}{c}62.13 \\
(40.82,83.44)\end{array}$ \\
\hline Netherlands & $\begin{array}{c}-3.97 \\
(-15.56,7.61)\end{array}$ & $\begin{array}{c}50.87 \\
(38.60,63.15)\end{array}$ & $\begin{array}{c}32.46 \\
(19.70,45.21)\end{array}$ & $\begin{array}{c}19.14 \\
(5.06,33.22)\end{array}$ & $\begin{array}{c}-1.68 \\
(-16.19,12.83)\end{array}$ & $\begin{array}{c}9.83 \\
(-4.81,24.46)\end{array}$ \\
\hline Oman & $\begin{array}{c}-37.03 \\
(-71.30,-2.76) \\
\end{array}$ & $\begin{array}{c}-15.55 \\
(-47.49,16.70) \\
\end{array}$ & $\begin{array}{c}-18.93 \\
(-52.65,14.79) \\
\end{array}$ & $\begin{array}{c}55.14 \\
(22.33,87.95) \\
\end{array}$ & $\begin{array}{c}30.38 \\
(-2.12,62.88) \\
\end{array}$ & $\begin{array}{c}46.12 \\
(11.91,80.34) \\
\end{array}$ \\
\hline Panama & $\begin{array}{c}-3.89 \\
(-57.80,50.02) \\
\end{array}$ & $\begin{array}{c}33.07 \\
(-27.38,93.52)\end{array}$ & $\begin{array}{c}65.10 \\
(-1.24,131.45)\end{array}$ & $\begin{array}{c}146.42 \\
(74.67,218.18)\end{array}$ & $\begin{array}{c}47.85 \\
(-13.35,31.90)\end{array}$ & $\begin{array}{c}84.82 \\
(3.31,66,33)\end{array}$ \\
\hline Portugal & $\begin{array}{c}3.61 \\
(-14.32,21.54)\end{array}$ & $\begin{array}{c}58.10 \\
(38.82,77.37)\end{array}$ & $\begin{array}{c}53.49 \\
(32.84,74.14)\end{array}$ & $\begin{array}{c}38.18 \\
(-16.53,59.83)\end{array}$ & $\begin{array}{c}9.28 \\
(12.31,57.09)\end{array}$ & $\begin{array}{c}60.04 \\
(36.28,83.80)\end{array}$ \\
\hline Romania & $\begin{array}{c}15.59 \\
(-1.30,32.48) \\
\end{array}$ & $\begin{array}{c}119.92 \\
(102.80,137.05) \\
\end{array}$ & $\begin{array}{c}64.82 \\
(47.94,81.70) \\
\end{array}$ & $\begin{array}{c}47.99 \\
(27.62,68.37) \\
\end{array}$ & $\begin{array}{c}34.70 \\
(-51.06,53.63) \\
\end{array}$ & $\begin{array}{c}48.39 \\
(26.59,70.18) \\
\end{array}$ \\
\hline Russia & $\begin{array}{c}-1.99 \\
(-22.75,18.77)\end{array}$ & $\begin{array}{c}-3.06 \\
(-28.98,22.86)\end{array}$ & $\begin{array}{c}-7.32 \\
(-37.53,22.89)\end{array}$ & $\begin{array}{c}-7.32 \\
(-41.19,26.64)\end{array}$ & $\begin{array}{c}-13.71 \\
(30.79,71.54)\end{array}$ & $\begin{array}{c}-19.04 \\
(-59.48,21.20)\end{array}$ \\
\hline $\begin{array}{l}\text { South } \\
\text { Africa }\end{array}$ & $\begin{array}{c}2.38 \\
(-11.58,16.34)\end{array}$ & $\begin{array}{c}48.09 \\
(32.62,63.55)\end{array}$ & $\begin{array}{c}82.09 \\
(65.21,98.98)\end{array}$ & $\begin{array}{c}60.04 \\
(41.46,78.63)\end{array}$ & $\begin{array}{c}51.16 \\
(-18.580,17.17)\end{array}$ & $\begin{array}{c}62.06 \\
(41.64,82.48)\end{array}$ \\
\hline Spain & $\begin{array}{c}-21.77 \\
(-35.70,-7.84)\end{array}$ & $\begin{array}{c}18.69 \\
(4.07,33.30) \\
\end{array}$ & $\begin{array}{c}23.70 \\
(8.43,38.97) \\
\end{array}$ & $\begin{array}{c}-3.21 \\
(-19.42,12.68) \\
\end{array}$ & $\begin{array}{c}0.69 \\
(-15.80,17.17) \\
\end{array}$ & $\begin{array}{c}4.53 \\
(-12.53,21.58) \\
\end{array}$ \\
\hline Sweden & -0.71 & -11.74 & 11.06 & -0.87 & -14.45 & 8.51 \\
\hline
\end{tabular}




\begin{tabular}{|c|c|c|c|c|c|c|}
\hline & $(-5.80,6.37)$ & $(-29.10,17.38)$ & $(2.06,19.45)$ & $(-11.26,13.21)$ & $(-31.23,2.03)$ & $(-6.21,19.28)$ \\
\hline UK & 1.77 & 75.56 & 80.54 & 52.29 & 55.50 & 30.30 \\
& $(-6.67,10.22)$ & $(65.95,85.18)$ & $(70.39,90.69)$ & $(41.51,63.06)$ & $(44.05,66.95)$ & $(19.47,41.13)$ \\
\hline USA & -11.70 & 25.29 & 42.63 & 30.10 & 26.77 & 21.61 \\
& $(-17.65,-5.76)$ & $(17.76,32.82)$ & $(34.54,50.72)$ & $(21.35,38.85)$ & $(18.40,35.13)$ & $(12.91,30.31)$ \\
\hline
\end{tabular}

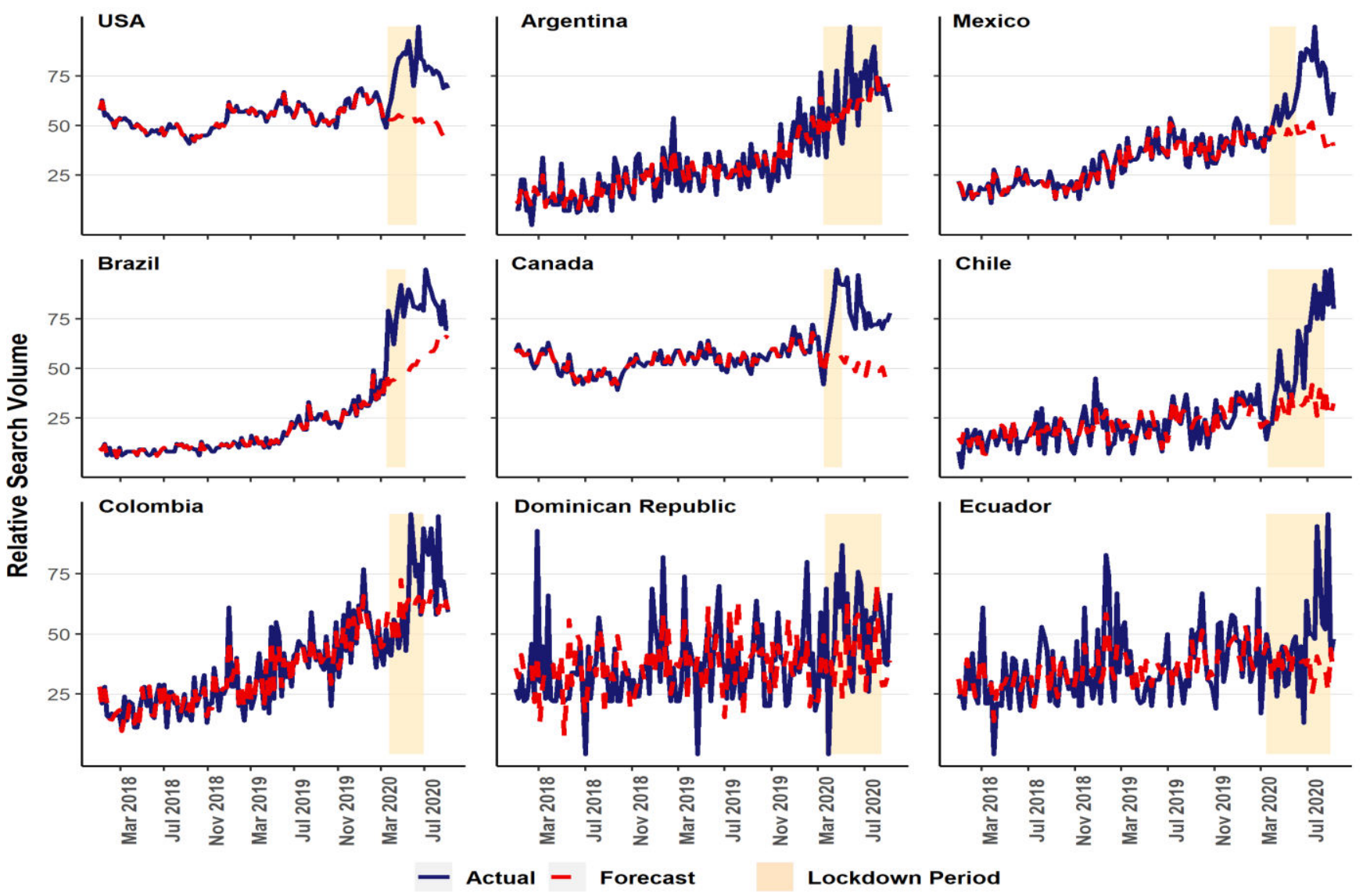

Fig 2: Actual and ARIMA forecasted mean RSV values in American countries.

Table 2: Multi-variate regression results.

\begin{tabular}{|c|c|c|c|}
\hline Coefficients & Estimate & Standard Error & P-value \\
\hline Constants & 6.710 & 8.310 & 0.46 \\
\hline Lockdown Measures & $\mathbf{3 . 6 8 1}$ & $\mathbf{1 . 4 1 1}$ & $\mathbf{0 . 0 4}$ \\
\hline COVID-19 cases per 100 thousand & $\mathbf{0 . 0 0 1}$ & $\mathbf{0 . 0 0 1}$ & $<\mathbf{0 . 0 1}$ \\
\hline Unemployment rate changes & -1.306 & 1.193 & 0.36 \\
\hline Skin disease related death per 100 thousand & 0.291 & 0.267 & 0.41 \\
\hline Internet usage percentage & 0.027 & 0.123 & 0.75 \\
\hline
\end{tabular}

\section{DISCUSSION:}

In summary, the illustration of Google Trends data in the result section clearly shows that there is a significant change in the public interest in skincare treatment during the COVID-19 pandemic. Most of the selected countries showed a significant increment in Google Trends mostly in May, specifically, during the lockdown period. However, countries of Asia expect Oman, Dominican Republic, and Russia showed UniversePG I www.universepg.com no significant change in public interests. These results suggest that people around the world have a concern about skincare treatment. This rapid skincare population interest in April and May might be triggered by worsening dermatological or cosmetic conditions as a consequence of irregular skincare treatment, limited supply, and dermatologists' un-availability during the lockdown period (Kutlu, 2020; Litchman and Rigel, 2020). 

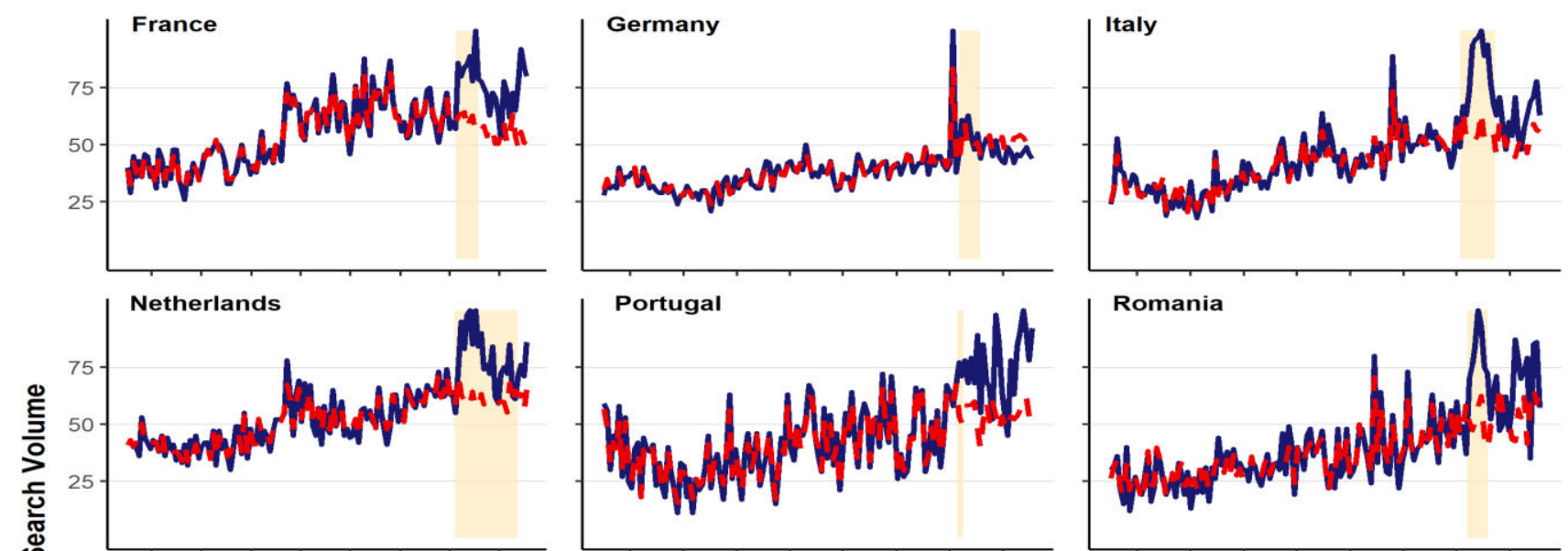

产
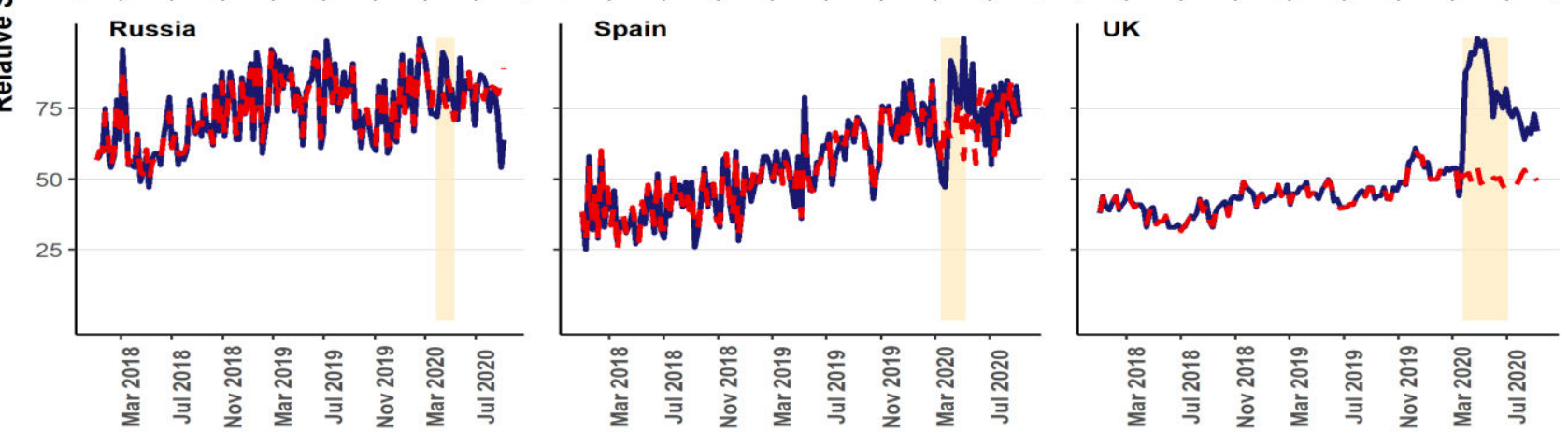

- Actual - Forecast

Lockdown Period

Fig 3: Actual and ARIMA forecasted skincare mean RSV values in European countries.

At the beginning period of the COVID-19 pandemic, both the public and health service providers faced challenges in care delivery while adhering to guidelines established by the Centers for Disease Control and Prevention. This might be the reason for web search decline for some dermatologic conditions and procedures reported in early pandemic period analysis contrasts to our results (Guzman and Barbieri, 2020; Searle, Al-Niaimi and Ali, 2020). Among the Americas countries, Chile showed the highest increment in RSVs for skincare in August (153.39\%). This large RSV value increment in Chile might be related to the longer lockdown (150 days) restriction. The longer lockdown in Chiliy has caused the sleeping problem, screen exposure, and behavioral appearance disturbance for some citizens (Majumdar, Biswas and Sahu, 2020; Pikoos et al., 2020). Of all American countries, the USA was hit hard by most COVID-19 cases and deaths according to the John Hopkins corona virus resource center (COVID-19 Data Repository by the Center for Systems Science and Engineering (CSSE). Johns Hopkins University, 2020). This surge of cases caused a huge impact on the healthcare system in the UniversePG I www.universepg.com
USA such as in diabetics to care, substantial racial and ethnic disparities, and cognitive heart failure (Bode et al., 2020; Morray et al., 2020; Tai et al., 2020). Similar to these health conditions, the dermatology patients were also affected by the sudden surge of COVID-19 patients and lockdown measures. In the USA, more than $50 \%$ of the dermatology outpatients decreased during the lockdown period and which might be a reason for the upward trend for skincare web search (Litchman and Rigel, 2020). After the USA, Brazil was the second country in the Americas which was mostly affected by COVID-19. The Google Trends for Brazil also followed the same way the USA went in the lockdown period. The Google Trends for skincare in the UK showed the highest increment of all selected European countries. The trends started to increase when the lockdown was first imposed in the UK and reached the highest increment on April 26 (80.54\%). A similar study showed that Google Trends for mental health deterioration also reached the highest increment in late April during the lockdown. (Pierce et al., 2020) This similarity in April suggests that the highest increment in the UK could be happened due to the 
lockdown measures. Besides the UK, this similar increment in trends was also found in Italy, France, and Belgium. In Italy, dermatological surgery patients in the restricted zone were reduced by approximately more than $45 \%$ (Gironi et al., 2020). This decline of patients may be the reason behind the continuous RSVs increment in Italy similar to the prior study (Kutlu, 2020). Despite the surge of COVID-19 cases and deaths, Russia and Spain the only two countries showed little change in RSVs increment. However, this unexpected change in Russia may be related to Google's lower search engines market share $(<60 \%)$ compared to other European countries. From the analysis of Google Trends, it can be inferred that skincare outpatients have decreased during this COVID-19 pandemic. Therefore, people with skin problems need proper healthcare directions. For such a case, Telehealth might provide a probable solution to the skincare patients which is being widely used during this pandemic (Smith et al., 2020; Wosik et al., 2020). The effectiveness of Telehealth has already been seen as patients surveillance in reducing the mental health burden, reducing exposure of obstetric patients, and surgical post-operative care, etc (Aziz et al., 2020; Hakim et al., 2020; Spiegelman et al., 2020; Zhou et al., 2020). Just like Telehealth, Teledermatogy could also provide patient surveillance for the skin disease patients (Gupta, Ibraheim and Doan, 2020). In addition, Teledermatogy would be a very useful service for those patients who are living in the rural side of the world (Vaidya et al., 2018). However, along with Telehealth, Teledermatogy has some limitations such as inadequate technical infrastructure, unequal reimbursement, and legal problems causing the delay of progress (Bull et al., 2016; Wang et al., 2020). This study has some limitations. First, people who don't have access to the internet excluded from this study which could bring significant change to Google Trends. However, since approximately $60 \%$ of the world population (4.57 billion people) are actively using the internet, it can be inferred that this population might be sufficient for skin disease patient surveillance (Dreher et al., 2018). Second, this study was done only based on one search engine (Google Search Engine), the other popular search engines like Baidu in China, and Yandex in Russia can give a better estimation for public interests (Noar et al., 2013; Liu et al., 2016). UniversePG I www.universepg.com
Third, Google Trends ignores typographical error in the query terms which could also change the trend, especially, people with fewer skills could be excluded from this study for such a case. Finally, the COVID-19 cases and deaths are changing every day so at the time of doing this research, Google Trends can change significantly. Besides, countries around the world are now reopening some of their imposed restriction measures which might also bring some significant change in Google Trends. (Zamir et al., 2020) Further research is needed to explore the actual sceario causing the increase of public interest in skin car treatment. Although the number of studies based on the google trend is increasing, Google does not provide detailed information about the procedures by which they generate search data, and the study population responsible for the searches remains unclear (Nuti et al., 2014). Besides, it is still unclear whether changes in online activity translate to changes in health behavior. Therefore, it is strongly recommended that Google trends should not be used as a sole replacement for robust disease surveillance and health literacy monitoring, rather it should be a real-time supplement to the comprehensive public interest monitoring (Venkatesh and Gandhi, 2020).

\section{CONCLUSION:}

In general, our study provides an assessment of skincare-related public interests during this COVID-19 pandemic period for the selected countries. The Google Trends analysis showed a significant increment in the public interest during COVID-19 time in 17 countries out of a total of 23 countries. Furthermore from the multivariate analysis, our study showed a positive increment of skincare-related RSV values with the increment of daily COVID-19 cases and lockdown measures after adjusting the covariates. The increment in public interests suggests the necessity of online contribution for skincare treatment. Since access to dermatologist care during lockdowns are scarce and limited in most countries, the increasing public search interests in skincare also suggests the need for additional and urgent medical care for untreated dermatological conditions. Finally, the analysis of Google Trends and the correlation between the COVID-19 pandemic and public interests for skincare can be help helpful for health service and skincare providers to analyze the present situation. 


\section{ACKNOWLEDGEMENT:}

We would like to thank Mostafizur Rahman MD, Medical officer, Residence Hospitals Limited for his assistance and tremendous support throughout the research work.

\section{CONFLICTS OF INTEREST:}

There is no conflict of interest.

\section{REFERENCES:}

1) Allauddin, Rehman G, Zarkoon AK, Nasira B, and Khan IU. (2021). COVID-19 pandemic lockdown resulting in an unusual rectal foreign body in a young male. Eur. J. Med. Health Sci., 3(6), 132-135.

https://doi.org/10.34104/ejmhs.021.01320135

2) Aziz, A. et al. (2020). 'Telehealth for High-Risk Pregnancies in the Setting of the COVID-19 Pandemic', American Journal of Perinatology, 37(8), pp. 800-808.

https://doi.org/10.1055/s-0040-1712121

3) Bernardo, T. M. et al. (2013). 'Scoping review on search queries and social media for disease surveillance: A chronology of innovation', J. of Medical Internet Research. https://doi.org/10.2196/jmir.2740

4) Bode, B. et al. (2020). 'Glycemic Characteristics and Clinical Outcomes of COVID-19 Patients Hospitalized in the United States', Journal of Diabetes Science and Technology, 14(4), pp. 813-821.

https://doi.org/10.1177/1932296820924469

5) Box, G. et al. (2015). Time series analysis: forecasting and control.

6) Bull, T. P. et al. (2016). 'Considerations for the Telehealth Systems of Tomorrow: An Analysis of Student Perceptions of Telehealth Technologies', JMIR Medical Education, 2(2), p. e11. https://doi.org/10.2196/mededu.5392

7) C. Heerfordt, I. M. H. (2020). 'Has there been an increased interest in smoking cessation during the first months of the COVID-19 pandemic? A Google Trends study', (January).

8) Compare Trends search terms (no date). https://support.google.com/trends/answer/4359550 ?hl=en\#zippy $=\% 2$ Ccompare-terms-acrosslanguages (Accessed: 1 January 2021).

9) COVID-19 Data Repository by the Center for Systems Science and Engineering (CSSE). Johns UniversePG I www.universepg.com
Hopkins University (2020). Available at: https://github.com/CSSEGISandData/COVID-19 (Accessed: 8 August 2020).

10) Dong, E., Du, H. and Gardner, L. (2020). 'An interactive web-based dashboard to track $\mathrm{CO}$ VID-19 in real time', The Lancet Infectious Diseases. Lancet Publishing Group, 20(5), pp. 533-534.

https://doi.org/10.1016/S1473-3099(20)30120-1

11) Dreher, P. C. et al. (2018). 'Use of Google Trends to Track Online Behavior and Interest in Kidney Stone Surgery', Urology. Elsevier Inc., 121, pp. 74-78.

https://doi.org/10.1016/j.urology.2018.05.040

12) Effenberger, M. et al. (2020). 'Association of the COVID-19 pandemic with Internet Search Volumes: A Google TrendsTM Analysis', International Journal of Infectious Diseases. https://doi.org/10.1016/j.ijid.2020.04.033

13) Ewusie, J. E. et al. (2020). 'Methods, applications and challenges in the analysis of interrupted time series data: A scoping review', Journal of Multidisciplinary Healthcare, 13, pp. 411-423. https://doi.org/10.2147/JMDH.S241085

14) Eysenbach, G. (2009). 'Infodemiology and infoveillance: framework for an emerging set of public health informatics methods to analyze search, communication and publication behavior on the Internet.', Journal of medical Internet research. Journal of Medical Internet Research, p. e1157. https://doi.org/10.2196/jmir.1157

15) Eysenbach, G. (2011). 'Infodemiology and infoveillance: Tracking online health information and cyberbehavior for public health', American Journal of Preventive Medicine. https://doi.org/10.1016/j.amepre.2011.02.006

16) Gironi, L. C. et al. (2020). 'The impact of COVID-19 pandemics on dermatologic surgery: real-life data from the Italian Red-Zone', Journal of Dermatological Treatment. Taylor \& Francis, 0(0), pp. 1-7. https://doi.org/10.1080/09546634.2020.1789044

17) Gupta, R., Ibraheim, M. K. and Doan, H. Q. (2020). 'Teledermatology in the wake of COVID-19: Advantages and challenges to continued care in a time of disarray', Journal of the American Academy of Dermatology. American 
Academy of Dermatology, Inc., 83(1), pp. 168169. https://doi.org/10.1016/j.jaad.2020.04.080

18) Guzman, A. K. and Barbieri, J. S. (2020). 'Analysis of dermatology-related search engine trends during the COVID-19 pandemic: Implications for patient demand for outpatient services and telehealth', Journal of the American Academy of Dermatology. Mosby Inc., 83(3), pp. 963-965. https://doi.org/10.1016/j.jaad.2020.05.147

19) Hakim, A. A. et al. (2020). 'Implications for the use of telehealth in surgical patients during the COVID-19 pandemic', American Journal of Surgery. Elsevier Inc., 220(1), pp. 48-49.

https://doi.org/10.1016/j.amjsurg.2020.04.026

20) Hudson, J., Fielding, S. and Ramsay, C. R. (2019). 'Methodology and reporting characteristics of studies using interrupted time series design in healthcare', BMC Medical Research Methodology. 19(1), pp. 1-7. https://doi.org/10.1186/s12874-019-0777-x

21) Jabaley, C. S. et al. (2018). 'Global trends in the awareness of sepsis: Insights from search engine data between 2012 and 2017', Critical Care. BioMed Central Ltd., 22(1), p. 7.

https://doi.org/10.1186/s13054-017-1914-8

22) JMIR Publications. E-collection 'Infodemiology and Infoveillance' (no date). Available at: https://www.jmir.org/collection/view/69

(Accessed: 2 February 2021).

23) JMIR Publications. E-collection 'Infoveillance, Infodemiology, Digital Disease Surveillance, Infodemic Management' (no date). Available at: https://publichealth.jmir.org/collection/view/304 (Accessed: 1 February 2021).

24) Kardeş, S. (2019). 'Seasonal variation in the internet searches for psoriasis', Archives of Dermatological Research. Springer Verlag, 311(6), pp. 461-467.

https://doi.org/10.1007/s00403-019-01921-0

25) Kardeş, S. et al. (2020). 'Population-level interest in anti-rheumatic drugs in the COVID-19 era: insights from Google Trends', Clinical Rheumatology. Springer Science and Business Media Deutschland GmbH.

https://doi.org/10.1007/s10067-020-05490-w

26) Kardeş, S. et al. (2021). 'Public interest in rheumatic diseases and rheumatologist in the
United States during the COVID-19 pandemic: evidence from Google Trends', Rheumatology International. Springer Science and Business Media Deutschland GmbH, 41(2), pp. 329-334. https://doi.org/10.1007/s00296-020-04728-9

27) Kutlu, Ö. (2020). 'Analysis of dermatologic conditions in Turkey and Italy by using Google Trends analysis in the era of the COVID-19 pandemic', Dermatologic Therapy, (July), pp. 16. https://doi.org/10.1111/dth.13949

28) Lin, Y., Liu, C. and Chiu, Y. (2020). 'Google searches for the keywords of "wash hands" predict the speed of national spread of COVID19 outbreak among 21 countries', (January), pp. 19-22.

29) Litchman, G. H. and Rigel, D. S. (2020). 'The immediate impact of COVID-19 on US dermatology practices', Journal of the American Academy of Dermatology. Elsevier, 83(2), pp. 685-686.

https://doi.org/10.1016/j.jaad.2020.05.048

30) Liu, K. et al. (2016). 'Using Baidu Search Index to Predict Dengue Outbreak in China', Scientific Reports, 6(November), pp. 1-9. https://doi.org/10.1038/srep38040

31) Majumdar, P., Biswas, A. and Sahu, S. (2020). 'COVID-19 pandemic and lockdown: cause of sleep disruption, depression, somatic pain, and increased screen exposure of office workers and students of India', Chronobiology International. Taylor \& Francis, 00(00), pp. 1-10. https://doi.org/10.1080/07420528.2020.1786107

32) MAvragani, A. (2020). 'Infodemiology and infoveillance: Scoping review', Journal of Medical Internet Research. JMIR Publications Inc., p. e16206. https://doi.org/10.2196/16206

33) Mavragani, A. and Ochoa, G. (2019). 'Google trends in infodemiology and infoveillance: Methodology framework', JMIR Public Health and Surveillance, 5(2), pp. 1-15. https://doi.org/10.2196/13439

34) Mavragani, A., Ochoa, G. and Tsagarakis, K. P. (2018). 'Assessing the methods, tools, and statistical approaches in Google trends research: Systematic review', Journal of Medical Internet Research. JMIR Publications Inc., 20(11), p. 
e270. https://doi.org/10.2196/jmir.9366

35) Morray, B. H. et al. (2020). 'Resource Allocation and Decision Making for Pediatric and Congenital Cardiac Catheterization During the Novel Coronavirus SARS-CoV-2 (COVID-19) Pandemic: A U.S. Multi-Institutional Perspective', The Journal of invasive cardiology, 32(5), pp. E103-E109.

36) Noar, S. M. et al. (2013). 'Using digital surveillance to examine the impact of public figure pancreatic cancer announcements on media and search query outcomes', Journal of the National Cancer Institute - Monographs, 44(47), pp. 188194.

https://doi.org/10.1093/jncimonographs/lgt017

37) Nuti, S. V. et al. (2014). 'The Use of Google Trends in Health Care Research: A Systematic Review', PLOS ONE. 9(10), p. e109583. https://doi.org/10.1371/journal.pone.0109583

38) Pierce, M. et al. (2020). 'Mental health before and during the COVID-19 pandemic: a longitudinal probability sample survey of the UK population', The Lancet Psychiatry. Elsevier Ltd, 7(10), pp. 883-892.

https://doi.org/10.1016/S2215-0366(20)30308-4

39) Pikoos, T. D. et al. (2020). 'The COVID-19 pandemic: Psychological and behavioral responses to the shutdown of the beauty industry', International Journal of Eating Disorders, pp. 1-10. https://doi.org/10.1002/eat.23385

40) Ravipati, A. and Pradeep, T. (2020). 'Seasonal variability in public searches of keratosis pilaris: How the internet can illuminate a pattern in public interest', Dermatologic Therapy. Blackwell Publishing Inc., 33(6).

https://doi.org/10.1111/dth.13957

41) Searle, T. N., Al-Niaimi, F. and Ali, F. R. (2020). 'Dermatological insights from Google Trends: what does the public think is important during COVID-19 lockdown?', Clinical and Experimental Dermatology. Blackwell Publishing Ltd, pp. 898-900.

https://doi.org/10.1111/ced.14319

42) Smith, A. C. et al. (2020). 'Telehealth for global emergencies: Implications for coronavirus disease 2019 (COVID-19)', Journal of Telemedicine and Telecare, 26(5), pp. 309-313.
https://doi.org/10.1177/1357633X20916567

43) Sofi-Mahmudi, A., Shamsoddin, E., Ghasemi, P., Nasser, M., et al. (2020). 'The association between COVID-19-imposed lockdowns and online searches for toothache using Google Trends', medRxiv. https://doi.org/10.1101/2020.08.01.20157065

44) Sofi-Mahmudi, A., Shamsoddin, E., Ghasemi, P., Bahar, A. M., et al. (2020). 'The association between lockdown due to COVID-19 epidemic and searches for toothache using Google Trends in Iran', medRxiv, p. 2020.08.06.20160515. https://doi.org/10.1101/2020.08.06.20160515

45) Spiegelman, J. et al. (2020). 'Rapid Development and Implementation of a Covid-19 Telehealth Clinic for Obstetric Patients'. https://doi.org/10.1056/CAT.20.0170

46) Stein-Zamir, C. et al. (2020). 'A large COVID19 outbreak in a high school 10 days after schools' reopening, Israel, May 2020', Eurosurveillance, 25(29), pp. 1-5.

https://doi.org/d10.2807/1560-7917.ES.2020.25. 29.2001352

47) Symum, H. and Mohammed, K. (2020). 'Monitoring COVID-19 related public Interest and population Health Literacy in South Asia: An Internet Search-Interest Based Model', medRxiv, (2), p. 2020.

https://doi.org/10.1101/2020.08.24.20180943

48) Tai, D. B. G. et al. (2020). 'The Disproportionate Impact of COVID-19 on Racial and Ethnic Minorities in the United States', Clinical Infectious Diseases, pp. 1-4. https://doi.org/10.1093/cid/ciaa815

49) The Journal of Medical Internet Research. Ecollection 'JMIR Theme Issue 2020/21: COVID19 Special Issue’ (no date). https://www.jmir.org/collection/view/923 (Accessed: 2 January 2021).

50) Timeline: WHO's COVID-19 response. World Health Organization, (2020). Available at: https://www.who.int/emergencies/diseases/novelcoronavirus-2019/interactive-timeline/ (Accessed: 8 November 2020).

51) Troelstra, S. A. et al. (2016). 'Effect of Tobacco Control Policies on Information Seeking for Smoking Cessation in the Netherlands: A 
Google Trends Study', PLOS ONE. Edited by L. Shahab. Public Library of Science, 11(2), p. e0148489.

https://doi.org/10.1371/journal.pone.0148489

52) Turkmen, D. et al. (2020). 'Evaluation of the effects of COVID-19 pandemic on hair diseases through a web-based questionnaire', Dermatologic Therapy, (June).

https://www.jmir.org/10.1111/dth.13923

53) Unemployment Insurance Weekly Claims Data. United States Department of Labor. (no date). https://oui.doleta.gov/unemploy/claims.asp

(Accessed: 8 April 2020).

54) Vaidya, T. et al. (2018). 'Socioeconomic and geographic barriers to dermatology care in urban and rural US populations', Journal of the American Academy of Dermatology, 78(2), pp. 406-408.

https://www.jmir.org/10.1016/j.jaad.2017.07.050

55) Venkatesh, U. and Gandhi, P. A. (2020).

'Prediction of COVID-19 outbreaks using google trends in India: A retrospective analysis', Healthcare Informatics Research, 26(3), pp. 175-184.

https://doi.org/10.4258/hir.2020.26.3.175

56) Walker, A., Hopkins, C. and Surda, P. (2020).
'Use of Google Trends to investigate loss-ofsmell-related searches during the COVID-19 outbreak', International Forum of Allergy and Rhinology, 10(7), pp. 839-847. https://doi.org/10.1002/alr.22580

57) Wang, C. et al. (2020). 'A novel coronavirus outbreak of global health concern', The Lancet. Lancet Publishing Group, 395(10223), pp. 470473.

58) Wang, R. H. et al. (2020). 'Clinical effectiveness and cost-effectiveness of teledermatology: Where are we now, and what are the barriers to adoption?', Journal of the American Academy of Dermatology. Elsevier Inc., 83(1), pp. 299-307. https://doi.org/10.1016/j.jaad.2020.01.065

59) Wosik, J. et al. (2020). 'Telehealth transformation: COVID-19 and the rise of virtual care', Journal of the American Medical Informatics Association, 27(6), pp. 957-962. https://doi.org/10.1093/jamia/ocaa067

60) Zhou, X. et al. (2020). 'The Role of Telehealth in Reducing the Mental Health Burden from COVID-19', Telemedicine and e-Health, 26(4), pp. 377-379.

https://doi.org/10.1089/tmj.2020.0068

\section{APPENDIX:}

Supplementary Table 1: Characteristics of the individual countries during the COVID-19 pandemic.

\begin{tabular}{|c|c|c|c|c|c|c|c|c|}
\hline Country & $\begin{array}{c}\text { Confirmed } \\
\text { Cases } \\
(/ \text { million})\end{array}$ & $\begin{array}{c}\text { COVID-19 } \\
\text { Death } \\
\text { (/million) }\end{array}$ & $\begin{array}{c}\text { Lockdown } \\
\text { Start } \\
\text { (Date) }\end{array}$ & $\begin{array}{c}\text { Lockdown } \\
\text { End } \\
\text { (Date) }\end{array}$ & $\begin{array}{c}\text { Lockdown } \\
\text { Duration } \\
(\text { Days })\end{array}$ & $\begin{array}{c}\text { Internet } \\
\text { Usage } \\
(\%)\end{array}$ & $\begin{array}{c}\text { Skin Death } \\
(/ 100000)\end{array}$ & $\begin{array}{c}\text { Lockdown } \\
\text { Style }\end{array}$ \\
\hline Argentina & 6389 & 125 & 20-Mar & 15-Aug & 149 & 75.81 & 3.38 & National \\
\hline Belgium & 6650 & 856 & 18-Mar & 4-May & 48 & 87.68 & 0.94 & State \\
\hline Brazil & 15595 & 504 & 17-Mar & 10-May & 55 & 71.86 & 2.48 & National \\
\hline Canada & 3226 & 239 & 17-Mar & 4-May & 49 & 92.7 & 0.59 & State \\
\hline Chile & 20061 & 543 & 19-Mar & 15-Aug & 150 & 82.33 & 1.51 & City \\
\hline Colombia & 8964 & 291 & 25-Mar & 30-Jun & 98 & 62.26 & 3.06 & National \\
\hline $\begin{array}{c}\text { Dominican } \\
\text { Republic }\end{array}$ & 7876 & 132 & 20-Mar & 15-Aug & 149 & 64.99 & 0.51 & National \\
\hline Ecuador & 5696 & 343 & 15-Mar & 31-Mar & 17 & 57.27 & 1.27 & National \\
\hline France & 3301 & 466 & 17-Mar & 11-May & 56 & 80.5 & 0.58 & National \\
\hline Germany & 2678 & 111 & 23-Mar & 10-May & 49 & 86 & 0.63 & National \\
\hline Iran & 4054 & 232 & 14-Mar & 20-April & 38 & 60.4 & 0.9 & National \\
\hline Italy & 4192 & 585 & 9-Mar & 28-May & 81 & 61.3 & 0.55 & National \\
\hline Kuwait & 17694 & 116 & 14-Mar & 29-Mar & 16 & 98 & 0.35 & National \\
\hline Mexico & 3961 & 433 & 23-Mar & 1-Jun & 71 & 63.82 & 2.19 & National \\
\hline
\end{tabular}




\begin{tabular}{|c|c|c|c|c|c|c|c|c|}
\hline Netherlands & 3646 & 360 & 13-Mar & 15-Aug & 156 & 93.2 & 0.58 & National \\
\hline Oman & 16191 & 110 & 10-Apr & 29-May & 50 & 80.19 & 3.37 & National \\
\hline Panama & 18368 & 401 & 25-Mar & 15-Aug & 144 & 57.87 & 2.37 & National \\
\hline Portugal & 5296 & 174 & 19-Mar & 2-Apr & 15 & 73.79 & 0.43 & National \\
\hline Romania & 3609 & 154 & 25-Mar & 12-May & 49 & 63.75 & 0.26 & National \\
\hline Russia & 6289 & 107 & 28-Mar & 12-May & 46 & 76.01 & 0.73 & City \\
\hline South Africa & 9826 & 197 & 26-sMar & 30-Apr & 36 & 56.17 & 4.52 & National \\
\hline Spain & 7675 & 612 & 14-Mar & 9-May & 57 & 84.6 & 0.96 & National \\
\hline Sweden & 8340 & 572 & - & - & - & 96.41 & 0.64 & - \\
\hline UK & 4672 & 609 & 23-Mar & 4-Jul & 104 & 94.62 & 1.2 & National \\
\hline USA & 16694 & 521 & 19-Mar & 10-Jun & 85 & 75.23 & 0.9 & State \\
\hline
\end{tabular}

Citation: Symum H, Islam MF, Hiya HK, and Ali KM. (2021). Impact of COVID-19 pandemic on populationlevel interest in skincare: evidence from a Google trends. Eur. J. Med. Health Sci., 3(6), 147-160. https://doi.org/10.34104/ejmhs.021.01470160 @) $\underset{\substack{\text { er } \\ \text { er }}}{ }$ 